\title{
Effect of Pre-Strain on The Longitudinal Residual Strain of Dissimilar Metal Welded Between Stainless Steel and Carbon Steel
}

\author{
Susilo Luhur Pambudi \\ Mechanical Engineering Department, Sebelas Maret University, Indonesia \\ Jl. Ir. Sutami 36A Surakarta, Indonesia. Tel: 62-27-163-2163
}

Triyono

Correspondence author, Mechanical Engineering Department, Sebelas Maret University, Indonesia Jl. Ir. Sutami 36A Surakarta, Indonesia. Tel: 62-27-163-2163

Email: triyonomesin@uns.ac.id

\author{
M. Refai Muslih \\ Neutron Scattering Lab., Center forTechnology of Nuclear Industrial Materials (BATAN), Serpong, Indonesia \\ Nurul Muhayat \\ Mechanical Engineering Department, Sebelas Maret University, Indonesia \\ Jl. Ir. Sutami 36A Surakarta, Indonesia. Tel: 62-27-163-2163
}

\begin{abstract}
Welding process is generally used in manufacturing industry. It usually produces distortions in the weld metal. To reduce distortion, one of the methods used is the pre-strain. This study aims to determine the effect of pre-strain during welding process on the residual strain of dissmilar metal weld between stainless steel and carbon steel. Gas Metal Arc Welding (GMAW) process is performed to make butt joint of SUS 304 stainless steel and SS 400 carbon steel with a length of $300 \mathrm{~mm}$, width of $150 \mathrm{~mm}$ and thickness of $5 \mathrm{~mm}$. Welding current, welding voltage and welding speed are $240 \mathrm{~A}, 24 \mathrm{~V}, 390 \mathrm{~mm} / \mathrm{min}$ respectively. During welding, stainless steel sheet is pre-strained in elastic, yield, and plastic levels. Strain measurements are performed using the neutron diffractometer which is conducted in Batan, Serpong, Indonesia. Pre-strain lead to increase the strain on the longitudinal direction of weld line. However, further away from the weld area, the strain decreases compared to the unpre-strained specimens.
\end{abstract}

Keywords: welding, pre-strain, distortion, residual strain, neutron

\section{Introduction}

Welding is the process of joining similar or dissimilar metals. Welding is done by applying heat or pressure or both, and with or without additional metal ${ }^{1}$. The welding heat will cause the locally temperature of the weld area is has a very high temperature, while the other has a lower temperature. This causes the temperature gradient in the welded plate. This phenomenon led to the expansion and contraction of the metal being welded which will affect the shrinkage of metal and cause distortion.

The control of the temperature distribution is essential to maintain the quality of the welded plate depends on many process parameters ie current, voltage and welding speed ${ }^{2}$. The welding also cause residual stresses in the welded metal. The residual stress caused due to non-uniform plastic deformation in a material, among others due to uneven heat treatment or cooling rate differences on materials that undergo the process of welding. Understanding the distortion in welded joints are very necessary to understand the phenomenon of failure in steel structures. Measurement of residual stress distribution in welded joints in order not to destroy, for example is the use of x-ray, sinkroton radiation or neutron ${ }^{3}$. Neutron diffraction gives a higher penetration of the steel surface to be measured residual stress. Neutrons have no electrical charge, the neutrons do not interact with electrons in the steel so they are able to penetrate deep into the steel. Transversal 
residual stress magnitude close to or equal to the yield strength of steel $\mathrm{S} 355 \mathrm{~J} 2 \mathrm{H}$. The magnitude of residual stresses transverse direction is greater than the longitudinal residual stress ${ }^{4}$. Detention of the plate during welding has a significant influence on the residual stress. The residual stress has a significant effect on the level of the rate of corrosion, fatigue and fracture ${ }^{5}$.

This research will study about effect of pre-strain to mechanical properties and longitudinal strain with neutron diffraction of dissimilar metal welded between stainless steel and carbon steel. The results of the welds was evaluated by strain measurement the neutron diffraction.

\section{Method}

\subsection{Welding materials and procedures}

In this study, the type of metal is SUS304 stainless steel and carbon steel SS400. The chemical composition and mechanical properties of SUS304 and SS400 can be seen in Table 1 and Table 2. Welding is used Gas Metal Arc-Welding (GMAW) or Metal Inert Gas (MIG). Weld joints using butt joint type. Pre-strain is only given during the welding process takes place. At the time of the pre-strain treatment, welding process started to reach the limits of the desired strain (Table 2).

Table 1. Chemical composition of SUS304 and SS400

\begin{tabular}{ccc}
\hline \multirow{2}{*}{ Elements } & \multicolumn{2}{c}{ Base Metal } \\
\cline { 2 - 3 } & SUS304 (\%) & SS400 (\%) \\
\hline $\mathrm{Fe}$ & 68,2 & 98,8 \\
$\mathrm{C}$ & 0,0467 & 0,0641 \\
$\mathrm{Si}$ & 0,841 & 0,0050 \\
$\mathrm{Mn}$ & 1,05 & 0,282 \\
$\mathrm{P}$ & 0,0613 & 0,0242 \\
$\mathrm{~S}$ & $<0,0050$ & 0,0098 \\
$\mathrm{Cr}$ & 16,3 & 0,0508 \\
$\mathrm{Mo}$ & 0,191 & 0,0761 \\
$\mathrm{Ni}$ & 12,3 & 0,175 \\
$\mathrm{Al}$ & 0,0220 & 0,0304 \\
$\mathrm{Co}$ & 0,0726 & 0,0312 \\
$\mathrm{Cu}$ & 0,507 & 0,0350 \\
$\mathrm{Nb}$ & 0,103 & 0,0370 \\
$\mathrm{Ti}$ & 0,0459 & $<0,0020$ \\
$\mathrm{~V}$ & 0,0397 & 0,0287 \\
$\mathrm{~W}$ & $<0,0250$ & 0,237 \\
$\mathrm{~Pb}$ & 0,0681 & $<0,0100$ \\
$\mathrm{Ca}$ & - & $<0,0001$ \\
$\mathrm{Zr}$ & - & 0,0178 \\
\hline
\end{tabular}

Source: Laboratory of Metal, Ceper, Klaten

Table 2. Mechanical Properties of SUS304 and SS400

\begin{tabular}{ccccccc}
\hline \multirow{2}{*}{$\boldsymbol{A} \boldsymbol{S} \boldsymbol{E}$} & \multicolumn{2}{c}{$\boldsymbol{\Delta L}(\mathbf{m m})$} & \multicolumn{2}{c}{$\boldsymbol{\varepsilon}=\left(\Delta \mathbf{L} / \mathbf{L}_{\mathbf{0}}\right) \mathbf{x} \mathbf{1 0 0} \%$} & \multicolumn{2}{c}{$\boldsymbol{\sigma}=\mathbf{P} / \mathbf{A}_{\mathbf{0}}\left(\mathbf{N} / \mathbf{m m} \mathbf{m}^{2}\right)$} \\
\cline { 2 - 7 } $\boldsymbol{M E T A L}$ & Yield & Max & Yield & Max & Yield & $\mathbf{M a x}$ \\
\hline SUS304 & 6,00 & 40,60 & 12,00 & 81,20 & 472,32 & 654,88 \\
SS400 & 1,49 & 10,81 & 2,98 & 21,61 & 300,36 & 363,38 \\
\hline
\end{tabular}

Source: Report of Testing, Materials Laboratory - UNS 
Table 3. Treatment of pre-strain on the SUS304

\begin{tabular}{ccc}
\hline Treatment & Pre-strain & $\begin{array}{c}\text { Time release of pre-strain } \\
\text { after welding }\end{array}$ \\
\hline 1. & $0 \mathrm{~mm}$ & 0 minute \\
2. & $3 \mathrm{~mm}$ (under yield) & 60 minutes \\
3. & $6 \mathrm{~mm}$ (yield) & 60 minutes \\
4. & $7 \mathrm{~mm}$ (upper yield) & 60 minutes \\
\hline
\end{tabular}

\subsection{Measurement of hardness}

Hardness expressed resistance to deformation and a measure of resistance of metal to plastic deformation or permanent deformation. Vickers hardness test uses a diamond pyramid indenter basically rectilinear shape. Large of angles between surfaces that face each other pyramid is $136^{\circ}$. Vickers hardness value is defined as the load divided by the surface area of the curve (equation 1).

$V H N=\frac{2 P \sin \left(\frac{\theta}{2}\right)}{d^{2}}=\frac{(1,854) P}{d^{2}}$

Where are $\boldsymbol{P}$ is the load used is $294 \mathrm{~N}, \boldsymbol{d}$ is the average diagonal length ( $\mathrm{mm}$ ), and $\boldsymbol{\theta}$ is the angle between the surface of the diamond face $136^{\circ}$.

\subsection{Strain measurement of longitudinal directions with neutron diffraction}

To determine the amount of strain that occurs in the samples was done by measuring the strain around the welding. Measurements were performed by using a neutron diffractometer (DN1-M) that is attached on the beam tube no. 6 (S-6) in RGS GAS (Reaktor Serba Guna G.A. Siwabessi) BATAN Serpong, Indonesia. Measurement points as shown in Fig 1. In the area of measurement is defined material into incident slits and receiving slits as shown in the Fig. 2 which is used to determine the lattice spacing between fields in a particular area with exact. This method using neutron diffraction to measure strain that occurs in the material being welded without damaging the weld material.

Neutron diffraction techniques exploit the crystal lattice of the material as a strain gauge atoms. When a neutron is passed through a polycrystalline material it will occur diffraction. Bragg's Law can be expressed by equation 2 to find the magnitude of the distance between $\mathrm{d}_{\mathrm{o}}$ the base metal crystals.

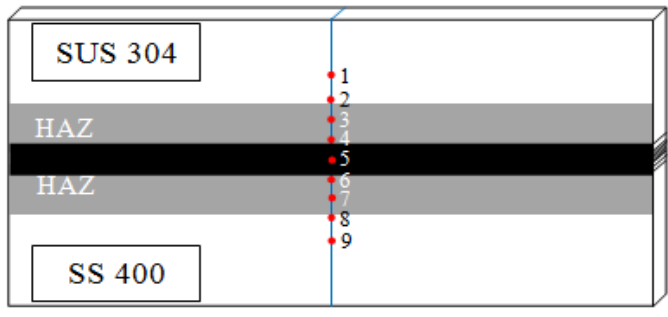

Fig 1. Picture of the measurement scheme

Information:
$\begin{array}{ll}1 \quad: \text { Base metal (SUS 304) } & 6: \text { Weld toe } \text { (SS 400) } \\ 2: \text { Base metal (SUS 304) } & 7: \text { HAZ (SS 400) } \\ 3: \text { HAZ (SUS 304) } & 8: \text { Base metal (SS } \\ 400) & \\ 4: \text { Weld toe (SUS 304) } & 9: \text { Base metal (SS } \\ 400) & \\ 5: \text { Fillet } & \end{array}$

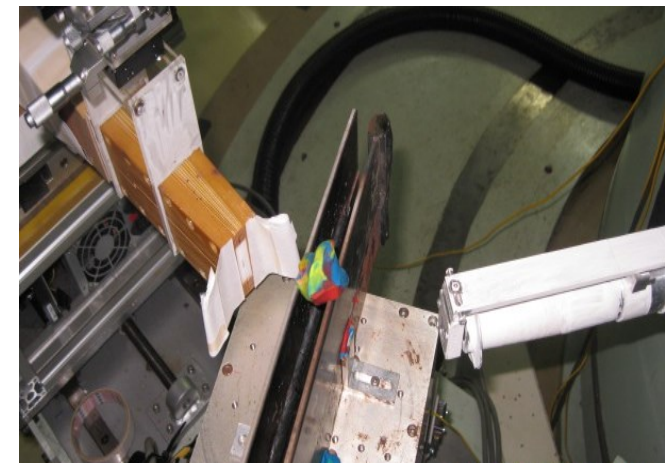

Fig. 2. Gauge volume in strain scanning method

$\lambda=2 \mathrm{~d} \sin \theta$

Wavelength of neutron $(\lambda)$ is 1,836 , angle neutron scattering $(\theta)$ is $27^{\circ}$ because of the material used has a field of 110. After $d_{o}$ and $d$ obtained large amount of strain can be obtained using the equation 3 .

$$
\varepsilon=\frac{d-d_{o}}{d_{o}}
$$




\section{Result}

\subsection{Hardness measurement}

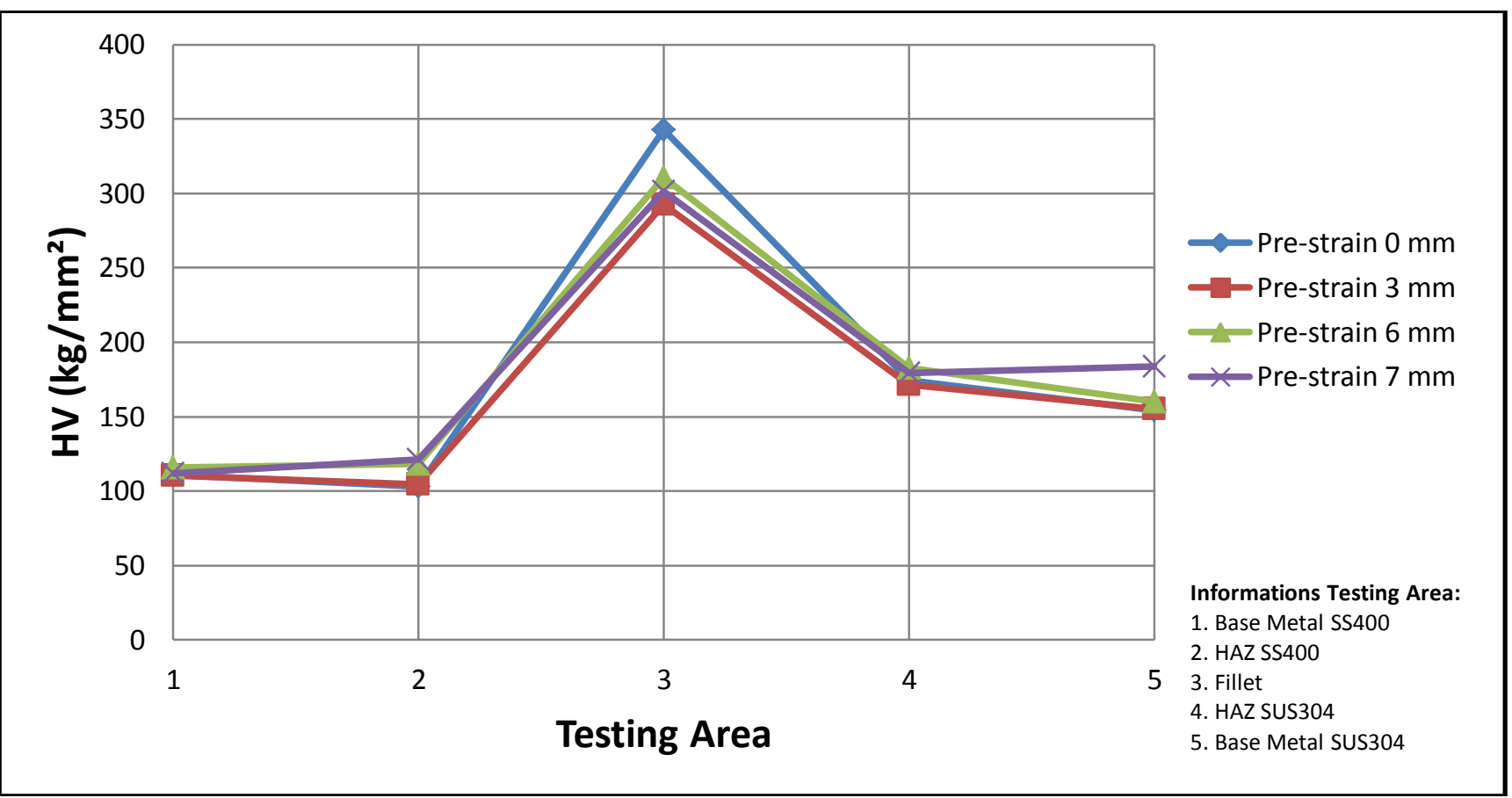

Fig 3. Graph vickers hardness values at the level of pre-strain

Weld hardness is measured on the base metal, HAS, and fillet (Fig 3).Generally, the highest hardness value lies in the fillet area and then decreased in the HAZ and base metal. For metals with pre-strain (SUS304) are impaired hardness of HAZ area to the base metal, but the metal without pre-strain (SS400) does not occur a significant decrease in hardness values of the HAZ to base metal area.

\subsection{Strain measurement}

Results welding strain is measured from the base metal, HAZ and weld. The measurements by neutron scattering at the center of the plate welds. The thickness of plate is $5 \mathrm{~mm}$, so that the position of the neutron bombardment at a depth of $2.5 \mathrm{~mm}$ below the surface of the plate. Figure 4 shows the neutron scattering fired specimen / plate.

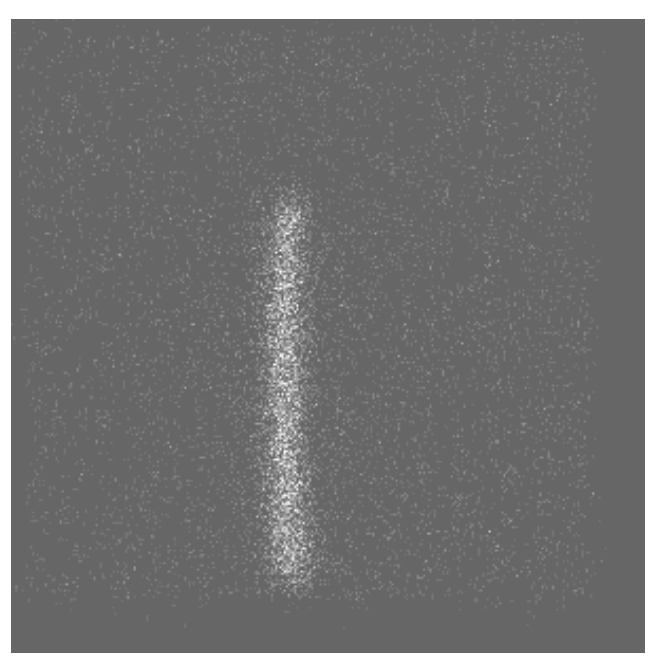

Fig 4. Scattering of neutrons are fired at the specimen 
From the results of Fig 4 are analyzed into Microsoft Excel Program. The results of data processing in Excel, then processed again using the origin 86 program so we get large graph and $\mathrm{x}_{\mathrm{c}}$ (maximum intensity) (Fig 5).

Then, maximum intensity is analyzed using equation 2.1 in order to obtain a large strain. Strain of each point will be obtained by graphic using Microsoft Excel (Fig 6)

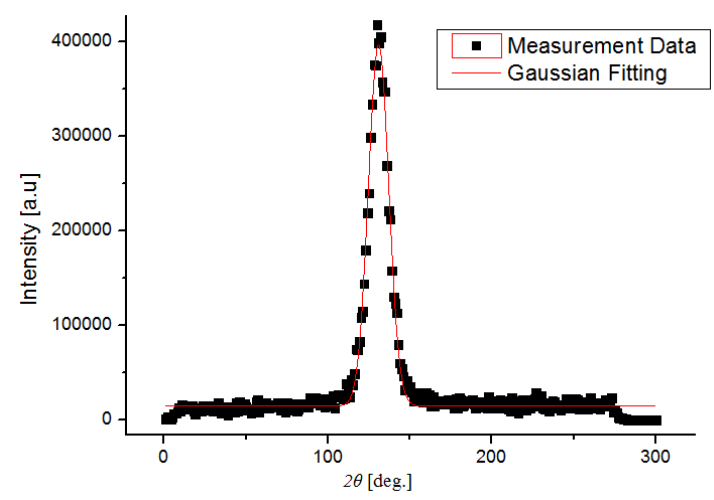

Fig 5. Chart intensity

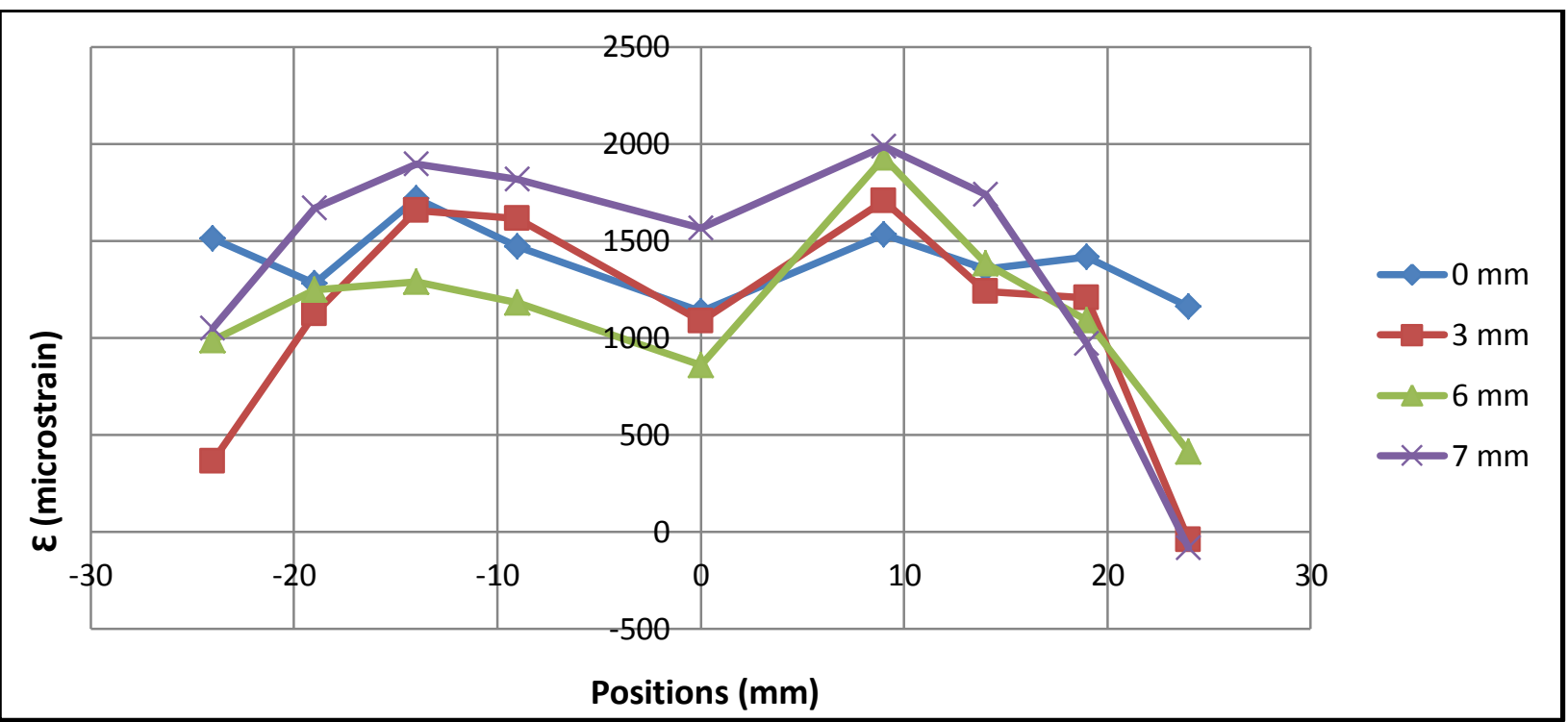

Fig 6. Graph of great strain neutron diffraction results

Positive area is part SUS304 plates were subjected to pre-strain, area 0 is the center of welding and negative areas are SS400 plate. From the center of the weld into weld to (limit the weld to HAZ) has a distance of $9 \mathrm{~mm}$, while the HAZ 1 is $14 \mathrm{~mm}, \mathrm{HAZ} 2$ was 19 $\mathrm{mm}$ and the base metal is $24 \mathrm{~mm}$.

\section{At position $24 \mathrm{~mm}$ (Base Metal of SUS304)}

The graph above explains that the presence of pre-strain will decrease the strain on base metal area. Pre-strain in upper yield $/ 7 \mathrm{~mm}$ (plastic area) has the lowest strain, followed by pre-strain under yield / $3 \mathrm{~mm}$ (elastic area) and followed pre-strain at yield / $6 \mathrm{~mm}$.

\section{At position $19 \mathrm{~mm}$ (Base Metal of SUS304)}

This position indicates that the pre-strain can reduce strain linearly according to the level of pre-strain.

\section{At position $14 \mathrm{~mm}$ (HAZ of SUS304)}

This position is the HAZ area. This position indicates that the pre-strain $3 \mathrm{~mm}$ (under yield) has a lower strain. The pre-strain at yield / $6 \mathrm{~mm}$ can increase the strain than without pre-strain treatments and increase again to the level of pre-strain up the yield / $7 \mathrm{~mm}$. 


\section{At position $9 \mathrm{~mm}$ (Weld toe of SUS304)}

Weld to area is the boundary of weld metal and base metal. This area has a tendency strain increases linearly with the level of pre-strain at base metal SUS304.

\section{At position $0 \mathrm{~mm}$ (Fillet)}

The fillet area shows phenomenon that the level of prestrain upper yield / $7 \mathrm{~mm}$ have the highest level of the strain and the level of pre-strain at yield / $6 \mathrm{~mm}$ has the lowest of the strain. While the level of pre-strain at the yield / $3 \mathrm{~mm}$ has a smaller strain compared to no prestrain treatments.

\section{At position $-9 \mathrm{~mm}$ (Weld toe of SS400)}

In this position indicates that the presence of pre-strain rate can increase the strain except the treatment of prestrain at yield / $6 \mathrm{~mm}$ which has the smallest strain.

\section{At position $-14 \mathrm{~mm}$ (HAZ of SS400)}

In this position it indicates that the presence of prestrain level can decrease the strain except the treatment of pre-strain upper yield / $7 \mathrm{~mm}$ which has the greatest of strain.

\section{At position -19 mm (Base Metal of SS400)}

This position indicates that the level of pre-strain under yield has the smallest strain, whereas the pre-strains upper the yield has the highest strain.

\section{At position -24 mm (Base Metal of SS400)}

The area of SS400 base metal has a tendency that the presence of the pre-strain can reduce the level of strain in a linear treatment.

\section{Conclusion}

With the level of pre-strain, the base metal SS400 was no increase hardness values, but at the HAZ hardness values increased SS400. In the fillet area is highest hardness values welding without pre-strain, while the HAZ and base metal SUS304 no increase or a significant decrease in hardness value with its level of pre-strain.

Using the neutron diffraction method, it can be measured strain at the welded plate. Treatment ot the pre-strain was found to increase the strain of the longitudinal direction at weld to (the boundary of weld metal and base metal). However, it is further away from the weld area strain decreased than with the untreated pre-strain. In future, we want to complete strain measurements at the transverse and normal direction, so it can be seen that the residual stress resulting from welding by treatment pre-strain.

\section{Acknowledgments}

Authors would like to express their sincere gratitude to Sebelas Maret University, Surakarta for financial support rendered through PNBP 2014 grant with contract no. 501/UN27.11/PN/2014

\section{References}

1. Arunkumar, N., Duraisamy, P., Veeramanikandan, S. (2012). Evaluation of Mechanical Properties Of Dissimilar Metal Tube Welded Joints Using Inert Gas Welding. Research and Applications (IJERA) ISSN: 2248-9622 www.ijera.com Vol. 2, Issue 5, SeptemberOctober 2012, pp.1709-1717.

2. Ghosh, A., Barman, N., Chattopadhyay, H., Hloch, S. (2013). A Study of Thermal Behaviour during Submerged Arc Welding. Journal of Mechanical Engineering 59(2013)5, 333-338.

3. Suzuki, T., Sugiyama, M., Oikawa, H., Nose, T., Imafuku, M., Tomota, Y., Suzuki, H., Moriai, A. (2011). Residual Stress Measurement of Welding Area by Neutron Diffraction Method. Nippon Steel Technical Report No. 100, UDC 539 . $419: 621.791 .763$. 1:539 .125 .5

4. Acevedo, C., Evans, A., Nussbaumer, A. (2012). Neutron diffraction investigations on residual stresses contributing to the fatigue crack growth in ferritic steel tubular bridges. International Journal of Pressure Vessels and Piping.

5. Price, J. W. H., Paradowska, A., Joshi, S., Finlayson, T. (2006). Residual stresses measurement by neutron diffraction and theoretical estimation in a single weld bead. International Journal of Pressure Vessels and Piping 83 (2006) 381-387 